\title{
Editorial
}

\section{Diabetes: Exploring social and psychological domain}

\author{
Ashok Kumar Das, Sanjay Kalra ${ }^{1}$ \\ Department of Medicine, JIPMER, Puducherry, ${ }^{1}$ Department of Endocrinology, Bharti Hospital and B.R.I.D.E., Karnal, India
}

The psychosocial aspects of diabetes (PSAD) care are increasingly occupying center stage in diabetology, and rightfully so. ${ }^{[1]}$ An increase in the prevalence of diabetes across age groups, gender, and nation societies enhanced understanding of the multifactorial biological basis of the disease, and an acute realization of the limitations of purely biology or pharmacology-based therapy have led to this trend. Policy makers now appreciate the public health and economic impact of diabetes. Researchers have unraveled patho-physiological defects, which provide a bridge between bio- and psycho-social aspects of diabetes, making it a perfect example for the bio-psycho-social model of disease. While pharmacologists have created novel therapeutic interventions based upon this research, clinicians appreciate (painfully) the truth that purely pharmacological approaches do not succeed in controlling diabetes. Our patients concur.

Psycho-social factors play an important role in the development, natural history, and management of diabetes. Detailed guidelines are available from various professional bodies, which encourage the assessment and management of general, psychological, psychiatric, and social factors, which impact glycemic control. ${ }^{[2]}$ While some of these documents are specific for children, others have universal coverage. Some documents provide generic overview of the subject, while others address cross-cultural issues and encourage patient-specific, community-specific intervention. In parallel with this development, qualitative, and mixed methods research are gradually being accepted as valid health research methodologies. ${ }^{[3,4]}$

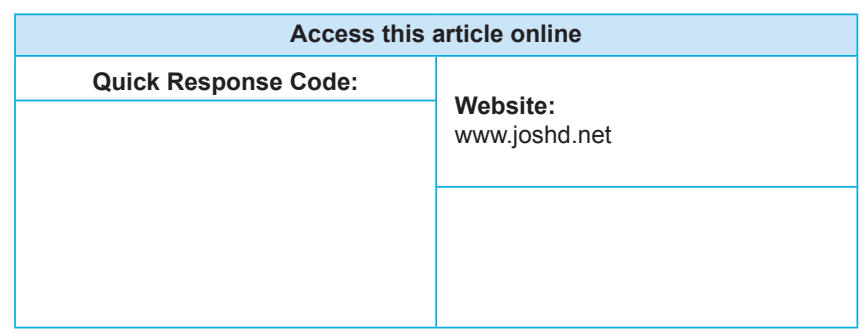

However, as a separate entity or sub-specialty, the science of PSAD faces certain hurdles. This subject has not grown as rapidly as obstetric diabetes. It has not received the same amount of attention as cardiovascular diabetology, eye disease, or renal disease has. Part of the reason may lie in its unwieldy nomenclature; PSAD is quite a mouthful. Other eponyms such as psycho-socio-diabetology or social and diabetology hardly fare better. The main reason, paradoxically, is the universal importance of PSAD; it affects every stakeholder in diabetes. Hence, no one takes ownership of this specialty. This is in contrast to the other subspecialties mentioned above, which are limited to particular age groups or to specific organ systems. Another factor, which has stymied the growth of PSAD, is its multidisciplinary nature, and the challenge of getting specialists from diverse field together to make a meaningful impact.

These challenges, however, need not be viewed as obstacles. Rather, they are stepping stones to achieving greater growth, using cross-discipline fertilization, while celebrating the diversity of diabetes. Better ideas and practices will be born, however, only if existing knowledge is disseminated. Best practice sharing, novel research, viewpoints, and commentaries, all have their role to play in this regards. In PSAD, as in other field of medicine, both clinical practice and research should complement each other. Mutual learning and improvement must be ensured by ensuring efficient sharing of knowledge. In today's technology-driven world, the open access model of publishing, using both online and print media, offers a convenient means of doing so. Our journal fits all these criteria.

As we work towards containing diabetes, PSAD need to be given adequate attention. Concerted, sustained, and efficient team work, involving all health care professionals and other stakeholders, is necessary if we are to take to make a meaningful impact. ${ }^{[5]}$ Every possible soldier must be mobilized to mitigate the effects of diabetes pandemic. 
Every diabetes care professional must be made aware of PSAD, sensitized to its importance, and empowered to optimize PSAD.

To contribute towards this goal, we present the inaugural issue of Journal of Social Health in Diabetes (JoSH-Diabetes) with confidence and pride. In many South Asian languages, the word JOSH means enthusiasm. A multidisciplinary, multi-continental compendium of articles, written in multiple styles, it brings the field of psycho-social aspects of diabetes to life. Each author exudes JoSH, or enthusiasm, through her or his words, and conveys the social health issues related to diabetes.

Through JoSH-Diabetes, we hope to achieve a significant impact in the psycho-social health of people with diabetes. We hope our patients will concur.

\section{REFERENCES}

1. Peyrot M, Rubin RR, Lauritzen T, SnoekFJ, Matthews DR, Skovlund SE. Psychosocial problems and barriers to improved diabetes management: Results of the Cross-National Diabetes Attitudes, Wishes and Needs (DAWN) Study. Diabet Med 2005;22:1379-85.

2. Kalra S, Sridhar GR, Balhara YP, Sahay RK. National recommendations: Psychosocial management of diabetes in India. In: Murugnathan A, editor. Medicine Update. Vol. 23. API; 2013. p. 209-14.

3. Glesne C. Becoming qualitative researchers: An introduction. Boston, USA: Pearson; 2011.

4. Creswell JW, Clark VL. Designing and conducting mixed methods research. Thousand Oaks, USA: Sage; 2011.

5. Conference Report: $2^{\text {nd }}$ International DAWN Summit; A call-to-action to improve psychosocial care for people with diabetes. Pract Diabetes Int 2004;21:201-8.

How to cite this article: ???

Source of Support: Nil. Conflict of Interest: None declared. 